\title{
ADOLESCENT HEAVY MENSTRUAL BLEEDING AND RESPONSE TO TREATMENT WITH REFERENCE TO BMI
}

Tulugu Sasikala ${ }^{1}$

${ }_{1}^{1}$ Assistant Professor, Department of Obstetrics and Gynaecology, RIMS, Srikakulam, Andhra Pradesh, India.

\section{ABSTRACT}

\section{BACKGROUND}

Adolescent heavy menstrual bleeding is excessive bleeding occurring in the age group of 13 - 19 years for more than 7 days or more than $80 \mathrm{~mL}$. The common cause for this is due to immaturity of HPO axis in the absence of any anatomical pathology. This condition is treated with Hormonal and Non-Hormonal drugs.

Aim: To study the effect of Body Mass Index on heavy menstrual bleeding and response to medical treatment in adolescent women.

\section{MATERIALS AND METHODS}

Adolescent women (13 - 19 yrs.) presenting with heavy menstrual bleeding to the Outpatient Department, Obstetrics and Gynaecology, RIMS, Srikakulam, during the study period meeting our inclusion criteria were included in this study. The data was collected using pre-designed questionnaire. BMI was calculated by formula: BMI $\left(\mathrm{kg} / \mathrm{m}^{2}\right)=$ Weight in $\mathrm{kg} / \mathrm{Height}$ in $\mathrm{m}^{2}$. After evaluation and taking an informed consent, patients were given medical treatment. Data was analysed with SPSS version 17.

\section{RESULTS}

The mean age of patients was $15.78+/-2.158$ yrs. The mean age at menarche of patients was 12.61 yrs. The mean duration of bleeding was $12.82 \pm 4.615$ days. Maximum being 35 days and minimum of 7 days. In our study, duration of bleeding had no significant relation with BMI. Out of 100 patients $86 \%$ of patients were having normal BMI and $71 \%$ underweight patients had regular cycles. $90 \%$ of patients who were overweight, and all the five obese patients included in this study had irregular cycles. The difference was statistically significant, i.e. as the BMI increases irregularity of cycles. 41 patients were treated with hormonal therapy and 47 patients were treated with non-hormonal therapy. 93.3\% patients who were normal weight and 85.71\% overweight adolescents responded to hormonal therapy. Response was $75 \%$ in obese individuals, showing that the response to hormonal therapy did not vary with BMI. The response to non-hormonal therapy significantly varied with BMI. Overall response to medical treatment did not vary with the BMI.

\section{CONCLUSION}

It is evident that BMI definitely effects the menstruation in adolescents. BMI has significant relation with the duration of heavy menstrual bleeding and also the menstrual irregularity. Incidence of anovulatory bleeding increases with increase in BMI.

\section{KEY WORDS}

Effect of BMI on Heavy Menstrual Bleeding, Adolescent Women, Response to Medical Treatment.

HOW TO CITE THIS ARTICLE: Sasikala T. Adolescent heavy menstrual bleeding and response to treatment with reference to BMI. J. Evolution Med. Dent. Sci. 2018;7(28):3243-3247, DOI: 10.14260/jemds/2018/729

\section{BACKGROUND}

Adolescent heavy menstrual bleeding is defined as excessive bleeding occurring from 13 to 19 years of age, ${ }^{1}$ when bleeding is prolonged ( $>7$ days) or excess blood loss of more than $80 \mathrm{~mL}$ per menstrual cycle. ${ }^{2}$

In up to $80 \%$ of cases, adolescent heavy menstrual bleeding is due to the immaturity of HPO axis in the absence of any anatomical pathology. ${ }^{3}$ HPO axis takes time to mature after menarche, up to $55-82 \%$ of cycles are anovulatory in the first two years after menarche and decrease to $20 \%$ of cycles at 4 years after menarche. ${ }^{4}$

'Financial or Other Competing Interest': None.

Submission 11-01-2018, Peer Review 23-06-2018,

Acceptance 01-07-2018, Published 09-07-2018.

Corresponding Author:

Dr. Tulugu Sasikala,

Assistant Professor,

SBI Officers Colony,

House No. 5-4-11,

Punyapu Street,

Srikakulam, Andhra Pradesh, India.

E-mail:dr.sasikala1963@gmail.com

DOI: $10.14260 /$ jemds $/ 2018 / 729$
FIGO classification of aetiology of AUB (PALM-COEIN: Ppolyps, A- adenomyosis, L- leiomyoma, M- malignancy, Ccoagulation abnormality- ovulatory causes, E- endometrial, Iiatrogenic, $\mathrm{N}$ - not yet determined) also applies for adolescents but structural causes like polyps, adenomyosis, fibroids (PALM) are rare in this age group.

An ovulation and bleeding disorders make up the vast majority of causes for HMB in adolescents. Other causes of heavy menstrual bleeding in adolescents include endocrine disorders like PCOS, hypo or hyperthyroids, Cushing syndrome and chronic infections. Body fat and obesity influence the menstrual cycle leading to menstrual irregularities. Overweight and obese adolescents are at risk of experiencing infrequent and longer periods. ${ }^{5,6}$

\section{Aetiology of Heavy Menstrual Bleeding?}

Diagnosis is made by thorough history taking and clinical evaluation. ${ }^{8}$ In $80 \%$ of cases, adolescent HMB is caused by immaturity of HPO axis leading to anovulatory cycles. 3,9 The complete maturation of the HPO axis may take up to 2 years. During this time, it is common for adolescents to present with abnormal uterine bleeding. ${ }^{10}$

1. Endocrinology.

2. Haematologic. 
3. Pregnancy complication.

4. Sexually transmitted infections/ pelvic inflammatory disease.

5. Medication.

6. Trauma.

7. Systemic illness.

Clinical Evaluation of Patients with Heavy Menstrual Bleeding

Upon physical examination height, weight, BMI, orthostatic blood pressure and pulse should be recorded. Examination of the major body system gives insight to endocrinology or systemic disease. Petechial haemorrhages and ecchymosed give evidence of a bleeding disorder. In sexually active adolescents complete pelvic examination should be performed to rule out trauma, pelvic infection, foreign body and pregnancy-related complications. ${ }^{11}$

\section{Laboratory Evaluation 12}

1. Common routine laboratory studies.

2. Secondary laboratory for patients unresponsive to therapy.

3. Imaging studies for patients unresponsive to therapy.

\section{Aims and Objectives}

1. To study the effect of BMI on heavy menstrual bleeding among adolescent women in a tertiary care hospital.

2. To study the response to medical treatment in patients with heavy menstrual bleeding in relation to BMI.

\section{MATERIALS AND METHODS}

Place of Study

RIMS General Hospital, Srikakulam.

\section{Type of Study}

Descriptive study.

\section{Study Population}

Consecutive adolescent women presented to our outpatient department who met the inclusion criteria as stated below during the study period.

\section{Sample Size}

As ours is a tertiary care centre, we get patients directly or through referrals from other hospitals. As per hospital statistics, we get 15 to 20 patients in adolescent clinic every month and $50 \%$ of them present with HMB. Among 134 adolescent girls presented with HMB, 100 were included in our study who fulfilled the inclusion criteria mentioned below.

\section{Duration of the Study}

March 2014 - May 2015.

\section{Inclusion Criteria}

- Age group: 13 - 19 yrs.

- Women with heavy menstrual bleeding with PBAC score more than 100 .

- Women who are willing for conservative management.

- Women with normal TSH in the last 6 months prior to study participation.

\section{Statistical Analysis}

- Data is statistically represented in terms of mean, median, percentages and range as required.

- Chi-square is used to test the significance of difference in two groups.

- Mean comparison between the groups is done by independent t-test.

- Probability (p-value) less than 0.05 is considered significant.

\section{RESULTS}

In our study, majority of cases i.e. $52 \%$ are in the age group of $13-15$ yrs.

\begin{tabular}{|c|c|c|c|c|c|}
\hline Age & Underweight & Normal & Overweight & Obese & Total \\
\hline $13-15$ & $6(11.5 \%)$ & $\begin{array}{c}32 \\
(61.5 \%)\end{array}$ & $\begin{array}{c}14 \\
(26.9 \%)\end{array}$ & 0 & 52 \\
\hline $15-17$ & 0 & $\begin{array}{c}12 \\
(66.6 \%)\end{array}$ & $\begin{array}{c}4 \\
(22.2)\end{array}$ & $\begin{array}{c}2 \\
(11.1 \%)\end{array}$ & 18 \\
\hline $17-19$ & $1(3.33 \%)$ & $15(50 \%)$ & $11(36.6 \%)$ & $3(10 \%)$ & 30 \\
\hline \multicolumn{7}{|c|}{ Table 1. Age at presentation in relation to BMI } \\
\hline
\end{tabular}

$\mathrm{P}$-value is 0.048 .

The mean age of patients was $15.78+/-2.158$ yrs. The mean age at menarche of patients is 12.61 yrs. The mean duration of bleeding is $12.82 \pm 4.615$ days. Maximum being 35 days and minimum being 7 days. In our study, duration of bleeding had no significant relation with BMI. The average age at menarche in underweight, normal, overweight and obese patients are 14.57 yrs., 12.66 yrs., 12.13 yrs. and 12.6 yrs. respectively.

\section{Duration from Menarche}

The mean duration from menarche to onset of HMB is 3.193 yrs. \pm 2.143 .

\begin{tabular}{|c|c|c|}
\hline $\begin{array}{c}\text { Duration from } \\
\text { Menarche }\end{array}$ & No. of Patients & Percentage \\
\hline Less than 1 year & 27 & $27 \%$ \\
\hline 1 to 3 years & 29 & $29 \%$ \\
\hline More than 3 years & 44 & $44 \%$ \\
\hline \multicolumn{2}{|c|}{ Table 2. Distribution of patients by duration from } \\
Menarche \\
\hline
\end{tabular}

$\mathrm{P}$-value is 0.052 .

Maximum number of patients, i.e. $56 \%$ presented within 3 years from menarche. The median is 3 years.

\section{Duration of Bleeding}

The mean duration of bleeding in relation to BMI in our study is $12.82 \pm 4.615$ days. Maximum being 35 days and minimum is 7 days.

\begin{tabular}{|c|c|c|c|c|}
\hline $\begin{array}{c}\text { Duration } \\
\text { of Flow }\end{array}$ & Underweight & Normal & Overweight & Obese \\
\hline$<10$ days & $1(4 \%)$ & $15(60 \%)$ & $7(28 \%)$ & $2(8 \%)$ \\
\hline $\begin{array}{c}10-15 \\
\text { days }\end{array}$ & $2(5 \%)$ & $24(60 \%)$ & $11(27.5 \%)$ & $3(7.5 \%)$ \\
\hline$>15$ days & $4(11.4 \%)$ & $20(57.1 \%)$ & $11(31.4 \%)$ & 0 \\
\hline \multicolumn{5}{|c|}{ Table 3. Duration of flow in relation to BMI } \\
\hline
\end{tabular}

$\mathrm{P}$-value is 1.000 . 


\section{BMI (Body Mass Index)}

The mean BMI is $23.1751+/ \_3.749 \mathrm{~kg} / \mathrm{m} 2$.

\begin{tabular}{|c|c|c|}
\hline BMI (kg/m2) & No. of Patients & Percentage \\
\hline$<18.5$ & 7 & $7 \%$ \\
\hline $18.5-24.9$ & 59 & $59 \%$ \\
\hline $25-29.9$ & 29 & $29 \%$ \\
\hline$>30$ & 5 & $5 \%$ \\
\hline \multicolumn{2}{|c|}{ Table 4. Distribution of Body Mass Index } \\
\hline
\end{tabular}

$\mathrm{P}$-value is 0.036 .

\section{Distribution of Anaemia in relation to BMI}

\begin{tabular}{|c|c|c|c|c|}
\hline $\begin{array}{c}\text { Grade of } \\
\text { Anaemia }\end{array}$ & Underweight & Normal & Overweight & Obese \\
\hline $\begin{array}{c}\text { Not } \\
\text { anaemic }\end{array}$ & $\begin{array}{c}3 \\
(9 \%)\end{array}$ & $\begin{array}{c}19 \\
(57.57 \%)\end{array}$ & $\begin{array}{c}9 \\
(27.2 \%)\end{array}$ & $\begin{array}{c}2 \\
(6 \%)\end{array}$ \\
\hline Mild & $\begin{array}{c}3 \\
(10 \%)\end{array}$ & $\begin{array}{c}18 \\
(60 \%)\end{array}$ & $\begin{array}{c}8 \\
(26.6 \%)\end{array}$ & $\begin{array}{c}1 \\
(3.33 \%)\end{array}$ \\
\hline Moderate & 1 & $\begin{array}{c}20 \\
(58 \%)\end{array}$ & $11(32.35 \%)$ & $\begin{array}{c}2 \\
(5.8 \%)\end{array}$ \\
\hline Severe & 0 & $2(66.6 \%)$ & $1(33.3 \%)$ & 0 \\
\hline Table 5. Distribution of Anaemia in relation to BMI \\
\hline
\end{tabular}

$\mathrm{P}$-value is 1.000 .

$64.4 \%$ of normal BMI women and $65.51 \%$ of overweight women had mild-to-moderate anaemia. Chi-square value is 2.334 and p-value is 1.000 at df of 9 showing insignificant relation with BMI.

\section{Treatment Given}

\begin{tabular}{|c|c|}
\hline Treatment Given & No. of Patients \\
\hline Non-Hormonal (53.4\%) & $\mathbf{4 7}$ \\
- Tranexamic acid & $8(17.02 \%)$ \\
-Tranexa+ iron & $25(53.19 \%)$ \\
-NSAIDs & $7(14.89 \%)$ \\
-NSAIDs + iron & $6(12.76 \%)$ \\
-Tranexa + blood & $1(2 \%)$ \\
\hline Hormonal (46.59\% ) & $\mathbf{4 1}$ \\
-POP & $3(7.31 \%)$ \\
-POP + iron & $17(41.46 \%)$ \\
-COC & $5(12.19 \%)$ \\
-COC + iron & $14(34.14 \%)$ \\
- POP + blood & $2(4.8 \%)$ \\
\hline Table 6. Number of patients and given Medications \\
\hline
\end{tabular}

\begin{tabular}{|c|c|c|}
\hline & Non-Hormonal & Hormonal \\
\hline Responded & $40(85.10 \%)$ & $36(87.80 \%)$ \\
\hline Not Responded & $7(14.89 \%)$ & $5(12.2 \%)$ \\
\hline \multicolumn{2}{|c|}{ Table 7. Overall response to Medical Therapy } \\
\hline
\end{tabular}

$\mathrm{P}$-value is 0.086 .

\begin{tabular}{|c|c|c|c|c|}
\hline & Underweight & Normal & Overweight & Obese \\
\hline Responded & 6 & 46 & 19 & 3 \\
\hline $\begin{array}{c}\text { Not } \\
\text { Responded }\end{array}$ & 0 & 6 & 7 & 1 \\
\hline \multicolumn{2}{|c|}{ Table 8. Overall response in relation to BMI } \\
\hline
\end{tabular}

$\mathrm{P}$-value is 0.025 .

\begin{tabular}{|c|c|}
\hline Response in Relation to BMI & Mean and SD \\
\hline Heavy Menstrual Bleeding (Responded) & $15.78 \pm 2.158$ \\
\hline $\begin{array}{c}\text { Heavy Menstrual Bleeding } \\
\text { (Not Responded) }\end{array}$ & $23.173 \pm 3.79$ \\
\hline \multicolumn{2}{|c|}{$\begin{array}{c}\text { Table 9. Response to Menstrual Bleeding } \\
\text { with reference to BMI }\end{array}$} \\
\hline
\end{tabular}

$\mathrm{P}$-value is 0.056 .

Oral progestin therapy can be effective, but is often poorly tolerated and therefore rarely used.13,14

In our study, $86.4 \%$ of patients of normal weight (BMI $18.5-24.9 \mathrm{~kg} / \mathrm{m}^{2}$ ) responded to non-hormonal therapy. Only $20 \%$ patients who were overweight $\left(25-29.9 \mathrm{~kg} / \mathrm{m}^{2}\right)$ responded to non-hormonal therapy. The response to nonhormonal therapy is good in normal BMI patients.

93.3\% patients who are normal weight and $85.71 \%$ overweight adolescents responded to hormonal therapy. Response is $75 \%$ in obese individuals. Since the Chi-square value is 1.265 with p-value $>0.05$ at the degree of freedom 3 . The difference is statistically insignificant showing that the response to hormonal therapy does not vary with BMI.

Up to $85.1 \%$ adolescents, i.e. 40 out of 47 patients responded to non-hormonal therapy, whereas in hormonal therapy response is $87.8 \%$ i.e. 36 out of 41 .

Overall, 74 out of 88 patients responded to medical treatment and $88.46 \%$ of normal BMI, $73 \%$ of overweight, $75 \%$ of obese patients responded to treatment.

\section{DISCUSSION}

Heavy menstrual bleeding in adolescence is one of most common causes for hospital visit in Gynaecology Outpatient Department.

This study included 100 consecutive patients of $13-19$ years' age group came to outpatient department with heavy menstrual bleeding who met our inclusion criteria. After taking an informed consent, patients were evaluated and given medical treatment and were followed up for three months and response was assessed in relation to BMI.

In this present study the mean age at menarche is 12.61 yrs., corresponds to Indian average (12.5 years). The mean age of menarche in underweight, normal, overweight and obese women are 14.57, 12.66, 12.13 and 12.6 yrs. respectively showing a descending trend with increasing BMI.

The mean age at presentation is 15.78 yrs. \pm 2.158 . Majority of patients, i.e. $52 \%$ belong to 13 - 15 years' age group and $73 \%$ present beyond 1 year from menarche. It is observed that menstrual disturbances occur commonly during first three to four years after menarche.

The mean duration of symptoms is $7.22 \pm 5.363$ months, minimum being 1 month and maximum 24 months. 57\% had symptoms of less than 6 months duration, 26\% had HMB for 6 to 12 months duration. $17 \%$ had HMB of more than 12 months duration.

In our study, overall $58 \%$ patients had regular and $42 \%$ had irregular cycles. Anaemia effects 30\% - 55\% of adolescents all over the world. Mean haemoglobin \% in our study is $11.29 \pm 1.567 \mathrm{gm} \%$ and $3 \%$ patients had $<8 \mathrm{gm} / \mathrm{dL}$ and were given inpatient management and blood transfusions. $30 \%$ patients had mild and 34\% had moderate anaemia and were given oral iron therapy. 33\% had $\mathrm{Hb} \%$ more than $12 \mathrm{gm} \%$. In our study, the relation between anaemia and BMI is found to be statistically insignificant. 
In our study, $21 \%$ patients had associated PCOS features on ultrasonography and majority were overweight and obese.

In our present study $40 \%$ patients had HMB associated with dysmenorrhoea, out of which $67.5 \%$ had normal BMI.

Medical management is the cornerstone in treatment of adolescent HMB and it can be hormonal or non-hormonal therapy depending on the need for regularisation of menstrual cycles and contraception and associated hyperandrogenic features. In our present study, 47 (53.4\%) patients were given non-hormonal therapy and 41 (46.59\%) patients were given hormonal therapy. 62 (70\%) patients who had mild-to-moderate anaemia were additionally given haematinics and for 3 patients with severe anaemia, blood transfusions were given along with specific therapy for HMB; 86 to $90 \%$ responded to non-hormonal and hormonal treatment respectively. The response to non-hormonal therapy showed significant difference with the BMI, but no statistically significant difference was observed in hormonal therapy with BMI in our study. The overall response to medical treatment did not show any statistically significant correlation with BMI.

\section{Summary}

In our study, the mean age at presentation with HMB is 15.78 yrs. \pm 2.158 and majority belong to $13-15$ yrs. The mean BMI in our study is $23.1751 \pm 3.749 \mathrm{~kg} / \mathrm{m}^{2} .59 \%$ girls were of normal BMI, 34\% were overweight and obese.

$90 \%$ of overweight patients had irregular cycles and $86 \%$ normal BMI patients had regular cycles. $21 \%$ patients had features of polycystic ovarian syndrome and of these majority were overweight.

$65 \%$ to $70 \%$ adolescents had mild-to-moderate anaemia. No significant difference in normal BMI and overweight girls is observed.

47 patients were given non-hormonal therapy and 41 patients were given hormonal therapy. $86.4 \%$ normal BMI girls responded to non-hormonal therapy, only $20 \%$ overweight patients responded to non-hormonal therapy. 93.1\% and $85.7 \%$ girls belonging to normal and overweight groups respectively responded to hormonal therapy. Response to non-hormonal therapy shows significant variation with BMI rather than response to hormonal therapy.

Overall response to medical treatment shows the probability value of more than 0.05 , i.e. no significant variation with BMI. As this is a hospital-based study the sample characteristics may differ from other field studies with respect to socio-economic status, educational status and the awareness which may influence the results. Hence, the association between BMI and response to medical treatment should be accessed through larger population-based studies.

\section{CONCLUSION}

There is no Statistically Significant difference in the Age at Presentation, with the BMI-

1. Duration of symptoms of $\mathrm{HMB}$ has a significant correlation with BMI.

2. There is significant relation between menstrual pattern and Body Mass Index. More the BMI, more irregular is the menstruation.
3. Response to non-hormonal treatment varies significantly with BMI, but no significant difference has been observed in the response to hormonal treatment in normal BMI and overweight patients in our study.

4. It is observed that the overall response to medical treatment does not vary with the BMI.

5. Medical management is the first line therapy for adolescent HMB. Response to medical treatment is good in both normal and overweight adolescents, but hormonal therapy appears to be necessary in overweight and obese adolescents for regularisation of cycles along with control of bleeding, though in our present study no significant statistical difference has been observed.

Present study has been selected because 'increasing childhood and adolescent obesity' has been proved to be a major risk factor for development of many medical issues like metabolic syndrome in adults. The clinical interventions that effectively address weight issues in adolescents may improve overall quality of life and other obesity related clinical outcomes. Screening during adolescence could provide an opportunity to target the group for promoting healthy life styles and early intervention to prevent future morbidities.

\section{REFERENCES}

[1] Prasad KHL, Manjunatha HK, Ramaswamy AS, et al. Adolescent menorrhagia: study of the coagulation profile in a tertiary centre in South India. Journal of Clinical and Diagnostic Research 2011;5(8):1589-92.

[2] Natalia RYDZ, Jamieson MA. Managing heavy menstrual bleeding in adolescents. Contemporary OB/GYN 2013;59(7):49. http://contemporaryobgyn.modernmedicine.com/aut horDetails/371001.

[3] Lethaby A, Farquhar C, Cooke I. Antifibrinolytics for heavy menstrual bleeding. Cochrane Database of Syst Rev 2000;(4):CD000249.

[4] Hertweck P, Yoost J. Common problems in paediatric and adolescent gynaecology. Expert Rev of Obstet \& Gynecol 2010;5(3):311-28.

[5] Dars S, Sayed K, Yousufzai Z. Relationship of menstrual irregularities to BMI and nutritional status in adolescent girls. Pak J Med Sci 2014;30(1):140-4. doi: 10.12669/pjms.301.3949. http://dx.doi.org/

[6] Deligeoroglou E, Karountzos V, Creatsas G. Abnormal uterine bleeding and dysfunctional uterine bleeding in paediatric and adolescent gynaecology. Gynecol Endocrinal 2013;29(1):74-8.

[7] Holland-Hall C. Heavy menstrual bleeding in adolescents: Normal variant or a bleeding disorder? Contemporary Obstet \& Gynecol 2013;58(1):34-47. http://contemporaryobgyn.modernmedicine.com/con temporary-obgyn/RC/menstruation/heavymenstrual-bleeding-adolescents.

[8] Warren MP, Vu C. Central causes of hypogonadism-functional and organic. Endocrinol Metab Clin North Am 2003;32(3):593-612.

[9] Khosla AH, Devi L, Goel P, et al. Puberty menorrhagia requiring inpatient admission. J Nepal Med Assoc 2010;49(178):112-6. 
[10] Koranne PS, Wahane AR. Puberty menorrhagia in modern era: analysis in a tertiary care centre. International Journal of Reproduction, Contraception, Obstetrics and Gynaecology 2014;3(3):622-6.

[11] Strickland JL, Wall JW. Abnormal uterine bleeding in adolescents. Obstet Gynecol Clin North Am 2003;30(2):321-5.

[12] Dangal G. Menstrual disorders in adolescents. The Internet Journal of Gynaecology and Obstetrics 2004;4(1).
[13] Sokkary N, Dietrich JE. Management of heavy menstrual bleeding in adolescents. Curr Opin Obstet Gynecol 2012;24(5):275-80.

[14] Wilkinson JP, Kadir RA. Management of abnormal uterine bleeding in adolescents. J Pediatr Adolesc Gynecol 2010;23(Suppl 6):S22-S30. 